\title{
The Finite Element Analysis of EBZ160 Running Mechanism of Road
}

\author{
Header \\ HongDong Ding \\ Guidaojiaotong Polytechnic Institute, Shenyang 110023, China
}

Keywords: heading machine, running gear, FEA.

Abstract. Through analyzing the force of the machine running gear and the calculation of its driving force, the strength of drive wheels is checked. To analyze the stress distribution and deformation of the driving wheel in working situation, the drive wheels working environment in Ansys is simulated. The results provide reference to optimum design of the machine structure.

\section{Introduction}

Walking mechanism is machine very important parts. The walking of heading machine is realized by the driving wheel and crawler board to cooperate with each other, When the driving wheel is driven by the gear reducer, rely on tooth profile in order to drive the track link segments of the walk [1]. Drive gear and segments with the same pitch, when the drive gear rotates, the base circle segments to match the drive gear on the base circle, each of the segments according to the same pitch on the drive gear transmission, implementation to walk. Transmission system and calculation of crawler plate design directly decides the walking performance [2]. This paper introduces the calculation method about machine line of driving force, driving wheels for the finite element analysis; provide a reference for the optimization of structural design [3].

\section{Design of the sprocket}

In order to reduce the direction of height, reduce the sprocket wheel diameter, need to change the original design of 13 teeth to 11, reduced the grounding Angle, the decrease of sprocket teeth directly reduce the sprocket wheel diameter.

$$
\begin{aligned}
& d=\frac{p}{\sin \frac{180}{z}} \\
& d_{a}=p\left(0.54+\cot \frac{180}{z}\right) \\
& d_{f}=d-d_{1}
\end{aligned}
$$

In the formula:

$\mathrm{d}$ - - Reference diameter, $\mathrm{mm}$;

$\mathrm{z}$ - - The teeth number of sprocket;

$d_{a}$ - Outside diameter, $\mathrm{mm}$;

$d_{\mathrm{f}}$ - - Root diameter, $\mathrm{mm}$; 
$d_{1}$ _ The thickness of the two tracks, mm.

$\mathrm{Z}=11, \mathrm{p}=160$ generation into the above formula:

$d=\frac{160}{\sin \frac{180}{11}}=567.91 \mathrm{~mm}$

$d_{a}=160 \times\left(0.54+\cot \frac{180}{11}\right)=615 \mathrm{~mm}$

$d_{f}=507.91 \mathrm{~mm}$.

3. Drive parameter calculation and design of tooth profile

Select reducer output torque $\mathrm{T}=66 \mathrm{KN}$, single biggest driving force:

$$
T_{\max }=2 T / d=232.8 \mathrm{kN}
$$

The tooth shape design of drive wheels for three circular arc in the same line, tooth figure as shown in the figure below:

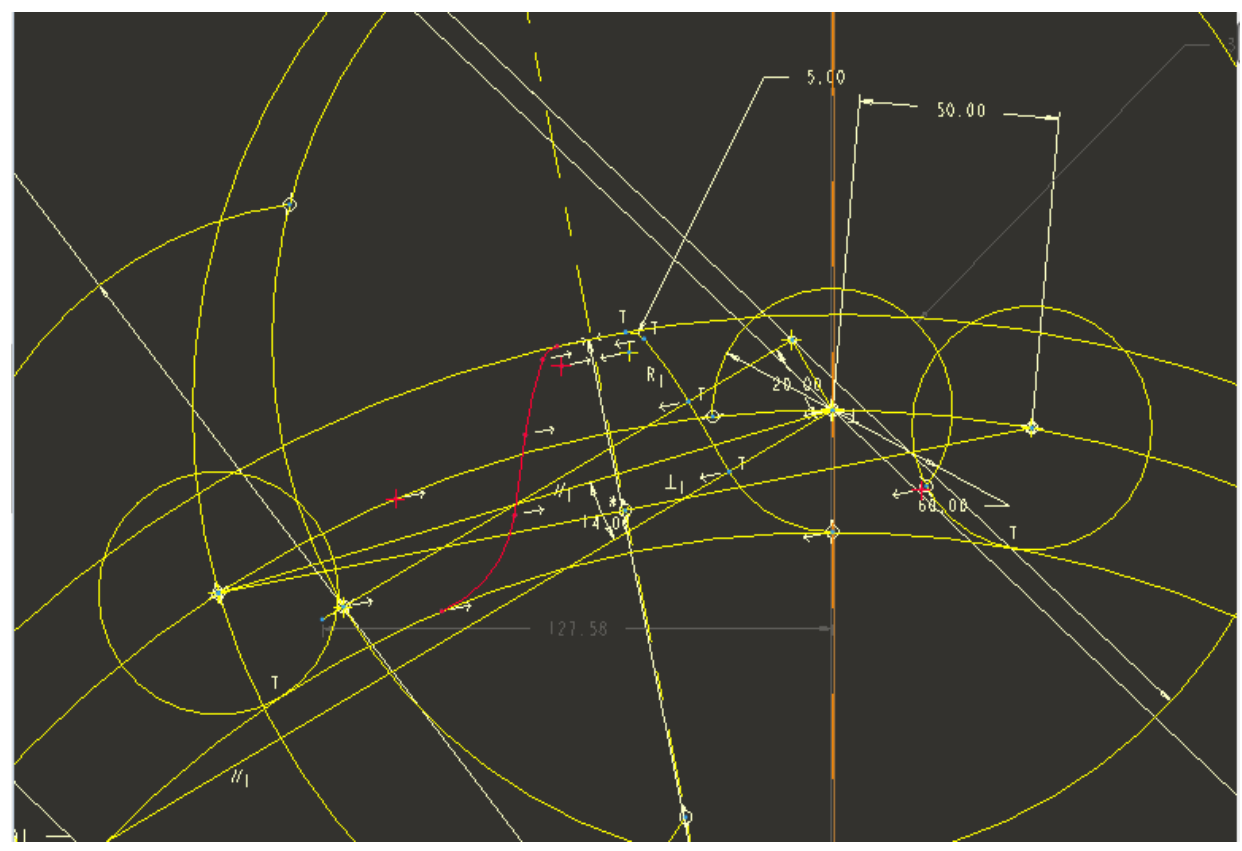

Fig.1 The tooth shape of the driving wheel

4. The condition analysis and load calculation of driving wheel

Driving wheels of the material is $42 \mathrm{CrMo}$, high frequency quenching, its material properties are as follows: elastic modulus is $2.2 \times 10^{5} \mathrm{Mpa}$, poisson's ratio is 0.3 , the density is $7.85 \times 10^{3} \mathrm{~kg} / \mathrm{m}^{3}$, the yield limit of 930MPa. Shell materials and attribute definitions: Material selection ZG25Mn2, elastic modulus of $1.99 \mathrm{GPa}$, poisson's ratio of 0.3 . Meshing the results are as follows: 


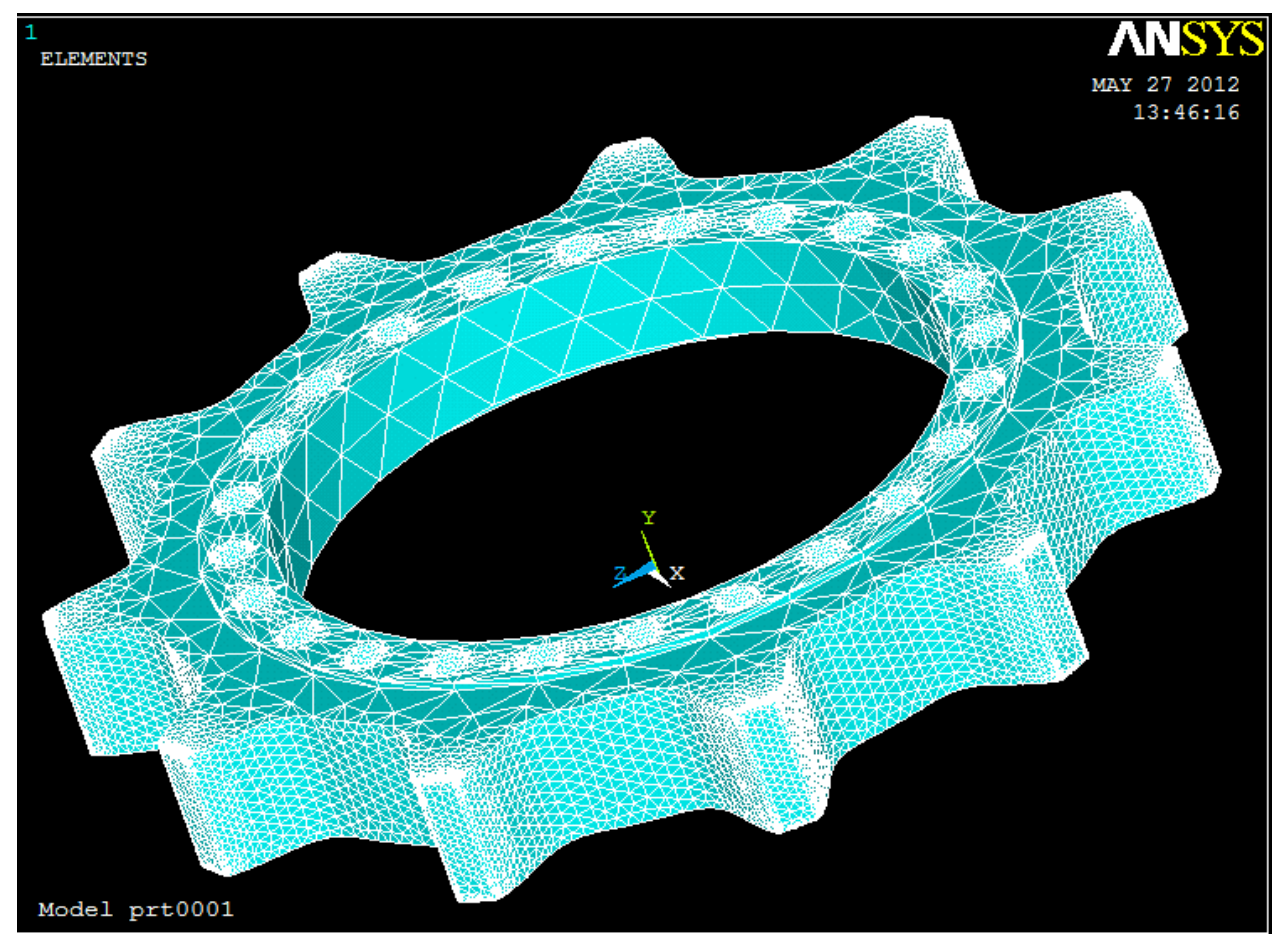

Fig. 2 The driving wheel meshing

When checking the intensity of driving wheel, in order to make the machine has higher reliability, the maximum output torque is provided by hydraulic motor as driving wheel drive torque [4]. When the travel agency work, the main impetus for walking machine provided by the hydraulic motor. The power that supplied by the motor through reducer is passed on to the drive wheels, drive caterpillar crawler walking [5]. Due to machine drives the caterpillar turn into small Angle $\left(3^{\circ} \sim 5^{\circ}\right)$, so its at the same time relay drivers drive tooth number for half of the total number of teeth, but in practice, As a result of the drive is not smooth, the transmission is not stable, cause there are a few teeth in heritability, here take extreme cases analysis, only used to force a tooth pass, to ensure the reliability of the machine is working.

(1) Load to determine: $\mathrm{T}=232.8 \mathrm{kN}$

(2) Constraint and load applied

Due to the driving wheel is the main transmission parts, bolts to connect to the reducer in the above work, the main part is close to the root and crawler board contact and interaction, the force on the part of the tooth, so choose load uniformly distributed load, the constraint and load applied as shown in the figure below.

The circumferential constraints of driving wheel are implemented by fastening bolt [6]. In actual work, because the number of bolt driving wheel force cannot be sure that the bolt stress is very complex, add method cannot be fixed constraint, here to select all 24 bolts was carried out on the driving wheel weeks to constraints, and to the drive wheels the deformation condition of stress distribution and stress distribution are analyzed [7]. 


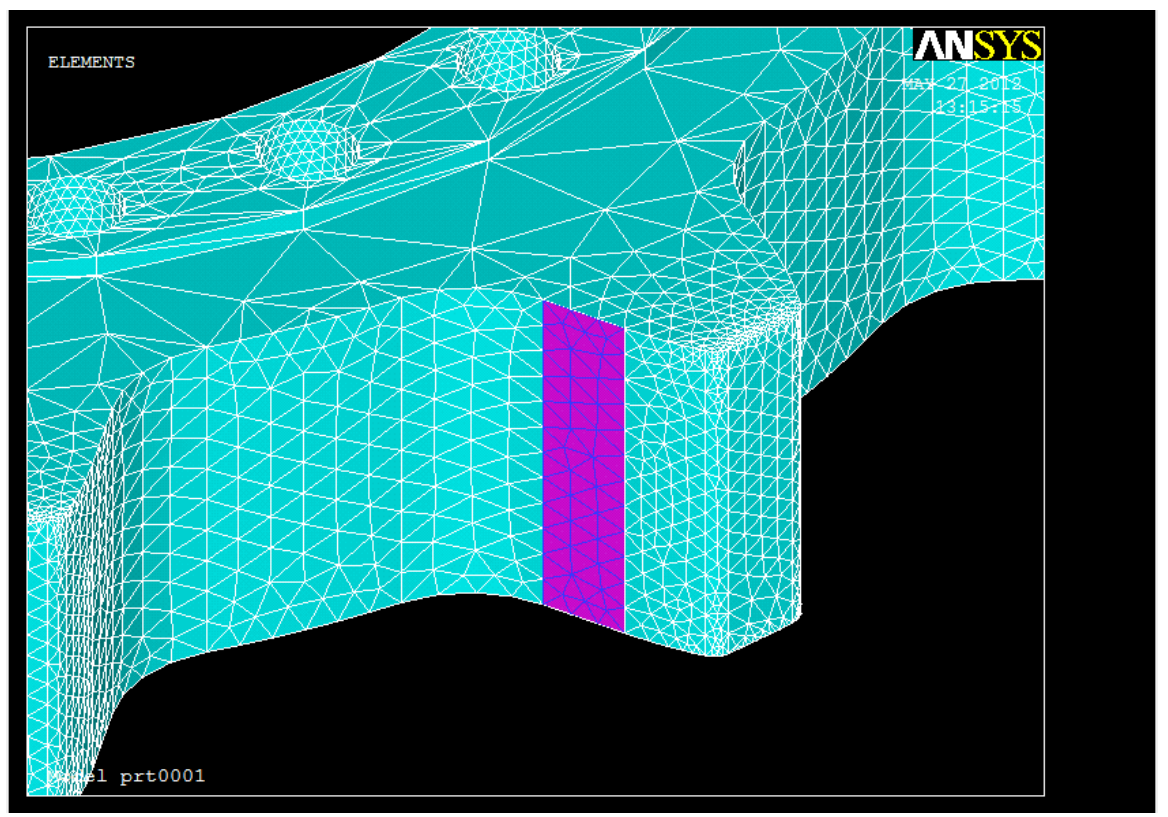

Fig.3 The constraint and load applied

\section{Summary}

In ansys, the static analysis was carried out on the driving wheel, the maximum stress is 188.094 $\mathrm{MPa}$, safety factor of 4.94. Analysis result shows that the driving wheel reserves sufficient strength with small deformation.It can meet the requirements. Conversely, if the tooth root stress becomes greater, we should focus on the Optimum design scheme.

\section{References}

[1] SHI.Meng, Research of Main Parameters and Hydraulic Control System for Crawler Mechanism of EBZ 160 Roadhead, J. Coal Mine Machinery.V01.30 No.6 Jun.2009 131-132.

[2] K.H.Gehring, M Fuchs,The ICUTROC Project-roadheaders for Hard Rock Applications and Influenceson Their Cutting Performance, J. CMMI Congress 2002/International Codes, Technology and Sustainahility for the Minerals Industry. 2002,P.113-121

[3] M.A.Kirkbride. Prediction of roadheader performance: A geotechnical assessment scheme, J. Ninth International Symposium on Mine Planning and Equipment Selection. 2000, P.607-612

[4] Kebire Kel, Nuri Akcin, H.Tuncdemir, cuttbaility Characteristics of Some High Strength Rocks for roadheader Selection in Zonguldak Coalfield, J. Mine Planning and equipment Selection. 2001, P.789-795

[5] J.G.Hetherington, Tracked vehicle operations on sand investigations at model scale, J. Journal ofTerramechanics. Volume 42, Issue 1,January 2005,Pages 65-70

[6] Stefan.Reh, Jean.Daniel.Beley, Siddhartha.Mukherjee, Eng Hui Khor, Probabilistic finite element analysis using ANSYS, J. Structural Safety, Volume28, Issues 1-2, January-April 2006, Pages 17-43.

[7] A.Ghorbanpour.Arani, R.Rahmani, A.Arefmanesh.,Elastic buckling analysis of single-walled carbon nanotube under combined loading by using the ANSYS software, J. Physica E: Low-dimensional Systems and Nanostructures, Volume 40, Issue 7, May 2008, Pages 2390-2395. 